VNU Journal of Science: Natural Sciences and Technology

Journal homepage: https://js.vnu.edu.vn/NST

Original Article

\title{
Chemical Composition of Essential Oil from the Leaves of Amentotaxus yunnanensis H.L. Li in Ha Giang Province
}

\author{
Tran Huy Thai ${ }^{1, *}$, Nguyen Thi Hien ${ }^{1}$, Le Ngoc Diep ${ }^{1}$, \\ Nguyen Trung Thanh ${ }^{2}$, Dinh Thi Thu Thuy ${ }^{3}$
}

\author{
${ }^{1}$ Institute of Ecology and Biological Resources, Vietnam Academy of Science and Technology, \\ 18 Hoang Quoc Viet, Hanoi, Vietnam
}

${ }^{2}$ VNU University of Science, Vietnam National University, Hanoi, 334 Nguyen Trai, Hanoi, Vietnam

${ }^{3}$ Insitute of Natural Products Chemistry, Vietnam Academy of Science and Technology, 18 Hoang Quoc Viet, Hanoi, Vietnam

Received 09 October 2019

Revised 09 January 2020; Accepted 06 February 2020

\begin{abstract}
The essential oil from the leaves of the Amentotaxus yunnanensis collected in Hoang Su Phi, Ha Giang province was obtained by hydrodistillation using a Clevenger apparatus and the yield of the essential oil was $0.01 \%$ from air-dry material. By using GC/MS analysis 50 constituents were identified, accounting for $88.96 \%$ of the essential oil. The main constituents were $\alpha$-pinene $(21.91 \%)$, kaur-16-ene $(13.03 \%), \alpha$-calacorene $(9.42 \%), \delta$-cadinene $(6.23 \%)$ and $\beta$-caryophyllene (4.9\%). This is the first study on the chemical constituents of essential oils from the leaves of Amentotaxus yunnanensis in Vietnam.
\end{abstract}

Keywords: essential oil, Amentotaxus yunnanensis, $\alpha$-pinene, kaur-16-ene, $\alpha$-calacorene, $\delta$-cadinene.

\footnotetext{
* Corresponding author.

Email address: thaiiebr@yahoo.com.vn

https://doi.org/10.25073/2588-1140/vnunst.4960
} 
VNU Journal of Science: Natural Sciences and Technology Journal homepage: https://js.vnu.edu.vn/NST

\title{
Thành phần hóa học của tinh dầu lá loài Dẻ tùng vân nam (Amentotaxus yunnanensis H.L. Li) từ Hà Giang
}

\author{
Trần Huy Thái ${ }^{1 * *}$, Nguyễn Thị Hiền ${ }^{1}$, Lê Ngọc Diệp ${ }^{1}$, \\ Nguyễn Trung Thành ${ }^{2}$, Đinh Thị Thu Thủy ${ }^{3}$ \\ ${ }^{I}$ Viện Sinh thái và Tài nguyên sinh vật,Viện Hàn lâm Khoa học và Công nghệ Việt Nam, \\ 18 Hoàng Quốc Việt, Hà Nội, Việt Nam \\ ${ }^{2}$ Đại học Khoa học Tư nhiên, Đại học Quốc gia Hà Nội, 334 Nguyễn Trãi, Hà Nội, Việt Nam \\ ${ }^{3}$ Viện Hóa học các hợp chất thiên nhiên,Viện Hàn lâm Khoa học và Công nghệ Việt Nam, \\ 18 Hoàng Quốc Việt, Hà Nội, Việt Nam \\ Nhận ngày 09 tháng 10 năm 2019 \\ Chỉnh sửa ngày 09 tháng 01 năm 2020; Chấp nhận đăng ngày 06 tháng 02 năm 2020
}

Tóm tắt: Tinh dầu từ lá của loài Dẻ tùng vân nam (Amentotaxus yunnanensis H.L. Li), thu tại Hoàng Su Phì, Hà Giang nhận được bằng phương pháp chưng cất lôi cuốn hơi nước sử dụng thiết bị Clevenger. Hàm lượng tinh dầu từ lá loài Dẻ tùng vân nam đạt $0,01 \%$ (theo nguyên liệu khô không khí). Bằng phương pháp sắc ký khối phổ (GC/MS), 50 thành phần hóa học của tinh dầu từ lá loài Dẻ tùng vân nam chiếm $88,96 \%$ tổng lượng tinh dầu đã được xác định. Thành phần chính của tinh dầu gồm: $\alpha$-pinene $(21,91 \%)$, kaur-16-ene $(13,03 \%), \alpha$-calacorene $(9,42 \%), \delta$-cadinene $(6,23 \%)$ và $\beta$-caryophyllene $(4,9 \%)$. Đây là dẫn liệu mới về thành phần hóa học của tinh dầu loài Dẻ tùng vân nam ở Việt Nam.

Từ khóa: Tinh dầu, Dẻ tùng vân nam, Amentotaxus yunnanensis, $\alpha$-pinene, kaur-16-ene, $\alpha$-calacorene, $\delta$-cadinene.

\section{Mở đầu}

Chi Dẻ tùng (Amentotaxus Pilg.) thuộc họ Thông đỏ (Taxaceae) có 6 loài trên thế giới phân bố chủ yếu ở Bắc Ấn Độ đến Đài Loan và Trung Quốc [1]. Ở Việt Nam, theo tài liệu của Nguyễn

\footnotetext{
* Tác giả liên hệ.

Địa chỉemail: thaiiebr@yahoo.com.vn

https://doi.org/10.25073/2588-1140/vnunst.4960
}

Đức Tố Lưu có 3 loài [2] và Nguyễn Tiến Hiệp có 4 loài, phân bố ở một số tỉnh phía Bắc Việt Nam và Tây Nguyên [2]. Một số loài được sử dụng làm thuốc chữa ung thư, làm cảnh, hạt có dầu béo $[1,2]$. Loài Dẻ tùng vân nam hay Dẻ tùng sọc trắng rộng (Amentotaxus yunnanensis H.L. 
Li) phân bố ở Lào Cai, Hà Giang, Yên Bái, Quảng Ninh còn có ở Trung Quốc.

Dẻ tùng vân nam là cây gỗ nhỏ đến trung bình, cao từ 15 đến $20 \mathrm{~m}$, đường kính ngang ngực $0,3 \mathrm{~m}$. Tán lá hình trứng rộng, cành xòe rộng và chếch về phía trên. Cành non màu lục, cành già màu vàng hay xám. Lá mọc gần đối xếp thành 2 hàng. Phiến lá dài $6-12 \mathrm{~cm}$, rộng 1-1,5 $\mathrm{cm}$, hình lưỡi mác hay hình dải hẹp. Nón cái đơn độc, mọc từ nách lá của các chồi ngắn. Nón đực mọc thành cặp hay thành chùm 4-6 ở ngọn cành nhỏ, dài $10-15 \mathrm{~cm}$, mỗi lá tiểu bào tử có 6-7 túi phấn. Hạt thường riêng lẻ ở cành hàng năm dài tới 2,8 cm, đường kính $1,4 \mathrm{~cm}$. Khi chín vỏ quả giả màu tím đỏ hơi có phấn trắng.

Cây mọc rải rác ở độ cao từ 700-1000 m trong rừng á nhiệt đới lá rộng. Cây mọc kèm cùng với một số cây lá kim như Pơ mu (Fokienia hodginsii), Thông tre lá dài (Podocarpus neriifolius), Bách vàng (Xanthocyparis vietnamensis), Thiết sam (Tsuga chinensis), ...[4,5].

Đã có một số công trình nghiên cứu trên thế giới về thành phần hóa học của loài $A$. yunnanensis. Theo Sheng-Hong Li và cộng sự (2003) thì các hợp chất chính được phân lập từ loài này là amentoflavon biflavonoid và abietane diterpenoid torreyayunmin [6]. Tuy vậy, chưa có công trình khoa học nào trên thế giới và trong nước nghiên cứu về thành phần hóa học tinh dầu các loài của chi Dẻ tùng. Trong bài báo này chúng tôi thông báo về thành phần hóa học của tinh dầu loài Dẻ tùng vân nam thu tại tỉnh Hà Giang.

\section{2. Đối tượng và phương pháp nghiên cứu}

Đối tượng nghiên cứu là lá của loài Dẻ tùng vân nam (Amentotaxus yunnanensis H.L. Li) thu vào tháng 4/2019 tại Hoàng Su Phì, Hà Giang. Ký hiệu mẫu TNTV 10. Mẫu được giám định tên khoa học bởi TS. Nguyễn Văn Hài và Tiêu bản mẫu trên được lưu giữ tại Viện Sinh thái và Tài nguyên sinh vật.

Hàm lượng tinh dầu (\%) được tính theo nguyên liệu khô không khí (khô ngoài không khí) và nguyên liệu khô tuyệt đối (nguyên liệu đã trừ độ ẩm, được sấy ở $100^{\circ} \mathrm{C} \div 105^{\circ} \mathrm{C}$ trong thời gian khoảng 30 phút cho khi khối lượng nguyên liệu không đổi), được tính theo công thức $\mathrm{X}=\mathrm{a}$ $\times 100 / b$ [a: thế tích tinh dầu $(\mathrm{ml})$, b: khối lượng nguyên liệu $(\mathrm{g})$ ] [7] và được xác định bằng phương pháp chưng cất lôi cuốn hơi nước có hồi lưu trong thiết bị Clevenger. Định tính và định lượng theo phương pháp sắc ký khí khối phổ $(\mathrm{GC} / \mathrm{MS})$. Tinh dầu được làm khan bằng $\mathrm{Na}_{2} \mathrm{SO}_{4}$ và để trong tủ lạnh ở nhiệt độ $<5^{\circ} \mathrm{C}$. Thiết bị GCMSD: Sắc ký khí Agilent 7890A ghép nối với Mass Selective Detector Agilent 5975C, cột HP$5 \mathrm{MS}$ có kích thước $(30 \mathrm{~m} \times 0,25 \mathrm{~mm} \times 0,25 \mu \mathrm{m})$. Chương trình nhiệt độ với điều kiện $60^{\circ} \mathrm{C}$ tăng nhiệt độ $4^{\circ} \mathrm{C} /$ phút cho đến $240^{\circ} \mathrm{C}$. Khí mang He. Nhiệt độ buồng chuyển tiếp là $270^{\circ} \mathrm{C}$, phá mảnh hoàn toàn với hiệu điện thế đầu dò là $70 \mathrm{eV}$, và dãy phổ 35-450Da ở 4 lần quét/giây. Các thành phần được xác định dựa trên hệ số lưu giữ của chúng (tính toán theo dãy đồng đẳng $n$-alkane) và so sánh phổ khối của chúng với dữ liệu phổ khối chất chuẩn lưu trong thư viện phổ (HPCH1607, NIST08, Wiley 09). Hàm lượng tương đối của các thành phần được tính toán dựa trên diện tích píc thu được từ sắc ký đồ. Phần mềm xử lý dữ liệu được sử dụng là Chemstation và phần mềm xử lý phổ khối là Mass Finder 4.0.

\section{Kết quả và thảo luận}

Hàm lượng tinh dầu từ lá loài Dẻ tùng vân nam đạt $0,01 \%$ (theo nguyên liệu khô không khí) và $0,023 \%$ (theo nguyên liệu khô tuyệt đối). Tinh dầu là chất lỏng có màu vàng nhạt, nhẹ hơn nước.

Từ Bảng 1 ta thấy, 50 hợp chất từ tinh dầu lá loài Dẻ tùng vân nam đã được xác định, Những thành phần chính của tinh dầu gồm: $\alpha$-pinene $(21,91 \%)$, kaur-16-ene $(13,03 \%), \alpha$-calacorene $(9,42 \%), \delta$-cadinene $(6,23 \%)$ và $\beta$-caryophyllene $(4,9 \%)$. Trong tinh dầu thì các hợp chất thuộc nhóm monoterpen và dẫn xuất chứa oxy chiếm 39,98\% và các hợp chất thuộc nhóm sesquiterpen và dẫn xuất chứa oxy chiếm $35,46 \%$ còn các hợp chất diterpen chỉ chiếm 13,39\% tổng lượng tinh dầu, các hợp chất thơm chiếm $0,13 \%$. 
Bảng 1. Thành phần hóa học tinh dầu từ lá Dẻ tùng vân nam

\begin{tabular}{|c|c|c|c|c|}
\hline STT & RI & $\mathrm{RI}^{\mathrm{a}}$ & Hợp chất & Hàm lượng (\%) \\
\hline 1. & 929 & 927 & tricyclene & 0,10 \\
\hline 2. & 930 & 930 & $\alpha$-thujene & 0,65 \\
\hline 3. & 940 & 939 & $\alpha$-pinene & 21,91 \\
\hline 4. & 953 & 953 & $\alpha$-fenchene & 0,21 \\
\hline 5. & 956 & 954 & camphene & 0,64 \\
\hline 6. & 979 & 975 & sabinene & 3,17 \\
\hline 7. & 985 & 979 & $\beta$-pinene & 0,70 \\
\hline 8. & 992 & 991 & myrcene & 2,02 \\
\hline 9. & 1016 & 1031 & $\delta$-3-carene & 3,24 \\
\hline 10. & 1022 & 1017 & $\alpha$-terpinene & 0,60 \\
\hline 11. & 1030 & 1026 & ortho-cymene & 1,35 \\
\hline 12. & 1034 & 1029 & limonene & 1,35 \\
\hline 13. & 1036 & 1030 & $\beta$-phellandrene & 0,65 \\
\hline 14. & 1064 & 1060 & $\gamma$-terpinene & 1,14 \\
\hline 15. & 1094 & 1089 & terpinolene & 0,74 \\
\hline 16. & 1103 & 1097 & linalool & 0,32 \\
\hline 17. & 1187 & 1177 & terpinen-4-ol & 0,99 \\
\hline 18. & 1200 & 1189 & $\alpha$-terpineol & 0,20 \\
\hline 19. & 1299 & 1287 & safrole & 0,13 \\
\hline 20. & 1367 & 1353 & $\alpha$-longipinene & 0,22 \\
\hline 21. & 1434 & 1421 & $\beta$-cedrene & 0,55 \\
\hline 22. & 1437 & 1419 & $\beta$-caryophyllene & 4,90 \\
\hline 23. & 1472 & 1455 & $\alpha$-humulene & 1,83 \\
\hline 24. & 1490 & 1480 & $\gamma$-muurolene & 0,22 \\
\hline 25. & 1492 & 1481 & ar-curcumene & 0,21 \\
\hline 26. & 1496 & 1485 & D-germacrene & 0,42 \\
\hline 27. & 1505 & 1490 & 1,11-oxidocalamenene & 1,81 \\
\hline 28. & 1521 & 1516 & $\beta$-curcumene & 0,21 \\
\hline 29. & 1530 & 1514 & $\gamma$-cadinene & 0,12 \\
\hline 30. & 1537 & 1523 & $\delta$-cadinene & 6,23 \\
\hline 31. & 1561 & 1546 & $\alpha$-calacorene & 9,42 \\
\hline 32. & 1565 & 1550 & elemol & 0,31 \\
\hline 33. & 1581 & 1566 & $\beta$-calacorene & 0,44 \\
\hline 34. & 1598 & 1578 & spathulenol & 0,37 \\
\hline 35. & 1605 & 1583 & caryophyllene oxide & 0,89 \\
\hline 36. & 1625 & 1608 & 5-epi-7-epi- $\alpha$-eudesmol & 0,32 \\
\hline 37. & 1628 & 1619 & epi-cedrol & 0,96 \\
\hline 38. & 1632 & 1608 & humulene epoxide II & 0,45 \\
\hline 39. & 1648 & 1629 & 1-epi-cubenol & 0,44 \\
\hline 40. & 1660 & 1640 & $\tau$-cadinol & 0,48 \\
\hline 41. & 1661 & 1642 & epi- $\alpha$-muurolol & 1,00 \\
\hline 42. & 1665 & 1646 & $\alpha$-muurolol & 0,18 \\
\hline 43. & 1673 & 1651 & $\beta$-eudesmol & 1,00 \\
\hline 44. & 1675 & 1654 & $\alpha$-cadinol & 0,56 \\
\hline 45. & 1676 & 1654 & $\alpha$-eudesmol & 0,40 \\
\hline 46. & 1678 & 1661 & cis-calamenen-10-ol & 0,33 \\
\hline 47. & 1687 & 1669 & trans-calamenen-10-ol & 0,29 \\
\hline 48. & 1696 & 1677 & cadalene & 0,90 \\
\hline 49. & 1997 & 1950 & pimara-8(14),15-diene & 0,36 \\
\hline \multirow[t]{6}{*}{50.} & 2080 & 2043 & kaur-16-ene & 13,03 \\
\hline & & & Tống & $88,96 \%$ \\
\hline & & & Các hợp chất monoterpen và dẫn xuất chứa oxy & $39,98 \%$ \\
\hline & & & Các hợp chất sesquiterpen và dẫn xuất chứa oxy & $35,46 \%$ \\
\hline & & & Hợp chât diterpen & $13,39 \%$ \\
\hline & & & Các hợp chất thơm & $0,13 \%$ \\
\hline
\end{tabular}

RI: Chỉ số lưu giữ (Retention index) tính toán bằng phần mềm của mẫu thực, RI ${ }^{\mathrm{a}}$ : tham khảo từ thư viện HPCH1607[8]. 


\section{Kết luận}

Hàm lượng tinh dầu từ lá loài Dẻ tùng vân nam đạt $0,01 \%$ (theo nguyên liệu khô không khí).

Bằng phương pháp sắc ký khối phổ (GC/MS), 50 thành phần hóa học của tinh dầu tù̀ lá loài Dẻ tùng vân nam (Amentotaxus yunnanensis $\mathrm{H}$.L. Li), chiếm 88,96\% tổng lượng tinh dầu đã được xác định. Những thành phần chính của tinh dầu gồm: $\alpha$-pinene $(21,91 \%)$, kaur-16-ene $(13,03 \%), \alpha$-calacorene $(9,42 \%), \delta$ cadinene $(6,23 \%)$ và $\beta$-caryophyllene (4,9\%).

\section{Lời cảm ơn}

Công trình được thực hiện nhờ sự hỗ trợ kinh phí của nhiệm vụ QTRU01.07/18-19 giữa Viện Hàn lâm Khoa học và Công nghệ Việt Nam với Quỹ Khoa học cơ bản Nga và đề tài Nafosted, Mã số: 106.06-2018.13.

\section{Tài liệu tham khảo}

[1] Võ Văn Chi, Useful plant dictionary, Vol. 1, Science and Tech. Publ. House Hanoi, 2003, pp. 265-266 (in Vietnamese).
[2] Nguyễn Đức Tố Lưu, Philip lan Thomas, Conifer plants of Vietnam, The World Publ. House, Hanoi, 2004 (in Vietnamese).

[3] Nguyê̂n Tiến Hiệp, Phan Kế Lộc, Nguyễn Đức Tố Lưu, Philip lan Thomas, Aljos Farjon, Leonid Averyanov, Jr. Jacinto Regalado, Conservation status of native conifer of Vietnam, The Social Labor Publ. House, Hanoi, 2004 (in Vietnamese).

[4] Phan Ke Loc, Pham Van The, Phan Ke Long, Regalado J, Averyanov L.V. and Maslin B, Native conifers of Vietnam - a review, Pak. J. Bot. 49(5) (2017) 2037-2068.

[5] Dominique Lesueur, Ninh Khac Ban, Ange Bighelli, Joseph Casanova, Analysis of the root oil of Fokienia hodginsii (Dunn) Henry et Thomas (Cupressaceae) by GC, GC-MS and ${ }^{13} \mathrm{C}$ NMR, Flavour Fragr. J. 21 (2005) 171-174.

[6] Sheng-Hong Li, Hong-Jie Zhang, Xue-Mei-Niu, Ping Yao, Han-Dong Sun and Harry H. S. Fong, Chemical constituents from Amentotaxus yunnanensis and Torreya yunnanensis, J. Nat. Prod. 66 (2003) 1002-1005.

[7] Ministry of Health, Vietnamese Pharmacopoeia, Vol. 1, The Medicine Publ. House, Hanoi, 1977, pp. 733-734 (in Vietnamese).

[8] Robert P. Adams, Identification of essential oil components by gas chromatography/quadrupole mass spectroscopy, Allured Publishing Corporation, USA, 2004. 